\title{
RELACIONES ENTRE POBLACIONES DE TEOCINTLE (ZEA SPP.) DE MÉXICO, GUATEMALA Y NICARAGUA
}

\author{
Guadalupe Torres Peña ${ }^{1}$, Lino De la Cruz Larios ${ }^{1,3}$, José de Jesús Sánchez \\ González ${ }^{1}$, José Ariel Ruiz Corral ${ }^{2}$, José Juvencio Castañeda Nava ${ }^{1}$, Fernando \\ Santacruz-Ruvalcaba ${ }^{1}$, Roberto Miranda Medrano ${ }^{1}$ \\ ${ }^{1}$ Universidad de Guadalajara, Centro Universitario de Ciencias Biológicas y \\ Agropecuarias, km 15.5 carretera Guadalajara-Nogales, 45110 Las Agujas, \\ Zapopan, Jalisco, México. \\ ${ }^{2}$ Instituto Nacional de Investigaciones Forestales Agrícolas y Pecuarias, Parque Los \\ Colomos s/n, Colonia Providencia, 44660 Guadalajara, Jalisco, México. \\ ${ }^{3}$ Autor para la correspondencia: linocucba@hotmail.com
}

\section{RESUMEN}

Se caracterizaron detalladamente poblaciones representativas de todas las razas, especies y subespecies conocidas de teocintle a fin de entender mejor sus relaciones y contribuir a resolver la taxonomía del género Zea. Se sembraron 95 accesiones en condiciones de invernadero en el Centro Universitario de Ciencias Biológicas y Agropecuarias (CUCBA) en el verano del 2011. Con base en las plantas obtenidas de esta manera, así como de su procedencia, se evaluaron 18 caracteres morfológicos y fisiológicos y 21 variables climatológicas con análisis de agrupamiento y de componentes principales (ACP). El uso combinado de los datos obtenidos y los análisis multivariados permitieron describir la gran complejidad de las relaciones entre poblaciones de diferentes especies de teocintle y de diversas zonas geográficas de México y América Central. Además de avanzar en aspectos taxonómicos, fue posible identificar con claridad las variables de mayor importancia, con base en la longitud de los vectores característicos derivados del análisis de componentes principales. La raza Balsas mostró la mayor diversidad morfológica y de adaptación. Dentro de la subespecie mexicana, hay una clara separación de las razas Chalco, Nobogame y Durango. Con base en los resultados, los límites de especies, subespecies y razas de teocintle encontrados son los siguientes: Zea nicaraguensis debe considerarse una subespecie de Zea luxurians, mientras que Zea luxurians de Oaxaca y Zea diploperennis de Huajicori, Nayarit son taxa diferentes del resto. Asimismo, Durango se considera una raza independiente de Mesa Central, mientras 
que la subespecie parviglumis corresponde a al menos dos razas, poblaciones adaptadas a altitudes inferiores a $1000 \mathrm{~m}$ y aquellas distribuidas entre 1000 y 1800 m s.n.m.

Palabras clave: diversidad morfológica, taxonomía numérica, teocintle, Zea.

\begin{abstract}
Teosinte populations representing all known races, species and subspecies were characterized in order to better understand their relationships and contribute to resolve the taxonomy of the genus Zea. Ninety-five teosinte accessions were grown during the summer of 2011 under greenhouse conditions at the Centro Universitario de Ciencias Biológicas y Agropecuarias (CUCBA). Eighteen morphological and physiological characters as well as 21 climatic descriptors were evaluated using Cluster Analysis and Principal Component Analysis (PCA). The combined data sets of morphological, physiological and climatic variables and the multivariate analysis helped to describe the complexity of the relationships between populations of different teosinte species and different geographical regions of Mexico and Central America. In addition to advancing the taxonomy of teosinte, the most important morphological and climatic variables defining the relationships were identified, based on the length of eigenvectors derived from PCA. The Balsas race of teosinte had the most variable morphology and adaptation. Within subsp. mexicana, the races Chalco, Nobogame and Durango are clearly differentiated. Results show that species, subspecies and race limits are as following: Zea nicaraguensis should be considered a subspecies of Zea luxurians, while Zea luxurians from Oaxaca and Zea diploperennis from Nayarit are two taxa different from the rest. Additionally, Durango is an independent race from the Mesa Central and subsp. parviglumis could be divided into two races, one including populations adapted to altitudes below $1000 \mathrm{~m}$ altitude, the others adapted to altitudes from 1000 to 1800 $\mathrm{m}$ above sea level.
\end{abstract}

Key words: morphological diversity, numerical taxonomy, Zea.

\title{
INTRODUCCIÓN
}

México está ubicado en tercer lugar en el contexto mundial en diversidad biológica con aproximadamente 30000 especies de plantas. Una de las características más importantes de la flora de México es que $12 \%$ de los géneros y $50-60 \%$ de 
todas sus especies son endémicas (CONABIO, 2008), como es el caso de algunos representantes de teocintle (Zea spp.).

Los parientes silvestres más cercanos al maíz, conocidos colectivamente como teocintle, están representados por especies anuales y perennes diploides $(2 \mathrm{n}$ $=20)$ y tetraploides $(2 n=40)$. Se distribuyen naturalmente en áreas cálidas y semicálidas de México, Guatemala, Honduras y Nicaragua, en general en poblaciones aisladas de tamaños variables que ocupan desde menos de una hectárea hasta varios kilómetros cuadrados.

Los teocintles fueron descritos por primera vez en 1832 como Euchlaena mexicana Schrad. Durante el siglo XX se descubrieron las plantas perennes diploides y tetraploides y se encontraron nuevas variantes anuales.

Wilkes (1967) describió seis razas de teocintle de México y Guatemala basado en información etnobotánica, geográfica, citológica y aspectos morfológicos de las plantas. El término raza fue propuesto por Anderson y Cutler (1942) con la finalidad de clasificar la gran diversidad en el maíz. Esta categoría fue incorporada en los sistemas actuales de clasificación para las especies silvestres del género Zea, propuestos por Iltis y Doebley (1980) y Doebley (1983a, 1983b, 1990). Los trabajos de Iltis y Doebley (1980) y Doebley (1983a, 1983b) se basaron en caracteres morfológicos y ecológicos, mientras que el de Doebley (1990) consideró marcadores moleculares. Iltis y Benz (2000) estimaron que existían suficientes diferencias entre el teocintle de la planicie costera de Nicaragua y Zea luxurians del sureste de Guatemala para considerarlas especies distintas.

Con base en los trabajos anteriores, el género Zea contiene ocho taxa en dos secciones y cinco especies. La sección Luxuriantes, propuesta por Doebley e Iltis (1980), incluye las especies perennes Zea diploperennis Iltis, Doebley \& Guzmán y Zea perennis (Hitchc.) Reeves \& Mangelsd., y las anuales Zea luxurians (Durieu y Asch.) Bird, así como Zea nicaraguensis Iltis \& Benz. La sección Zea incluye a Zea mays L. dividida en las subespecies Zea mays subsp. mexicana (Schrad.) Iltis (razas Chalco, Mesa Central y Nobogame) -algunos autores reconocen la raza Durango, mientras que otros la consideran parte de la raza Mesa Central-, Zea mays subsp. parviglumis Iltis \& Doebley (raza Balsas), Zea mays subsp. huehuetenangensis (Iltis \& Doebley) Doebley (raza Huehuetenango) y Zea mays subsp. mays para maíz cultivado. Recientemente se describieron tres nuevos taxones de México dentro de la sección Luxuriantes (Sánchez et al., 2011).

En el estudio citado se consideró que las tres nuevas poblaciones constituyen combinaciones inusuales de caracteres morfológicos y fisiológicos para distinguirlos claramente de las especies descritas para el género Zea, aunque se indicó que 
sus relaciones son aún inciertas. Adicionalmente, existen varias poblaciones con características morfológicas y moleculares intermedias entre Zea mays subsp. parviglumis y Zea mays subsp. mexicana (Sánchez et al., 2011), además de controversias relativas a las relaciones de Zea mays subsp. huehuetenangensis y de Zea nicaraguensis con los demás teocintles.

El objetivo del presente trabajo es aclarar estas dudas, así como caracterizar morfológica y fisiológicamente poblaciones representativas de todos los taxa conocidos de teocintle a fin de entender mejor sus interrelaciones y contribuir a resolver la taxonomía del género Zea.

\section{MATERIALES Y MÉTODOS}

Material vegetal sembrado y sitio de estudio

El material genético considerado en este estudio incluyó cada una de las especies y razas conocidas de teocintle. En total se sembraron 95 accesiones en condiciones de invernadero en el Centro Universitario de Ciencias Biológicas y Agropecuarias (CUCBA) de la Universidad de Guadalajara, localizado en Nextipac, Jalisco, México en las coordenadas $20^{\circ} 45^{\prime}$ latitud $\mathrm{N}$ y $103^{\circ} 31^{\prime}$ longitud $\mathrm{O}$ y a una elevación de $1650 \mathrm{~m}$.

La mayor parte de la semilla de las poblaciones de teocintle fue colectada entre los años 2002 y 2010 y depositadas en el Banco de Germoplasma de la Universidad de Guadalajara y en el Instituto Nacional de Investigaciones Forestales y Agropecuarias (INIFAP). Algunas muestras fueron obtenidas del Centro Internacional de Mejoramiento de Maíz y Trigo. La distribución geográfica de las accesiones utilizadas y los datos de cada sitio se presentan en la Figura 1.

Descripción ecológica

El sistema de información ambiental (SIA) del INIFAP fue utilizado para caracterizar las condiciones climáticas de los sitios de colecta mediante el uso de IDRISI Selva (Eastman, 2012). Tal información del SIA se basa en valores numéricos calculados a partir de series de datos de los años 1961 al 2010.

Con base en las coordenadas geográficas de cada sitio de colecta se obtuvo información puntual por accesión, relacionada con las siguientes variables: Altitud en m s.n.m. (ALT); Número de días con temperatura mayor de $35{ }^{\circ} \mathrm{C}$; Temperatura máxima promedio anual (TXO); Temperatura máxima mayo-octubre; Temperatura mínima promedio anual; Temperatura mínima mayo-octubre; Temperatura prome- 


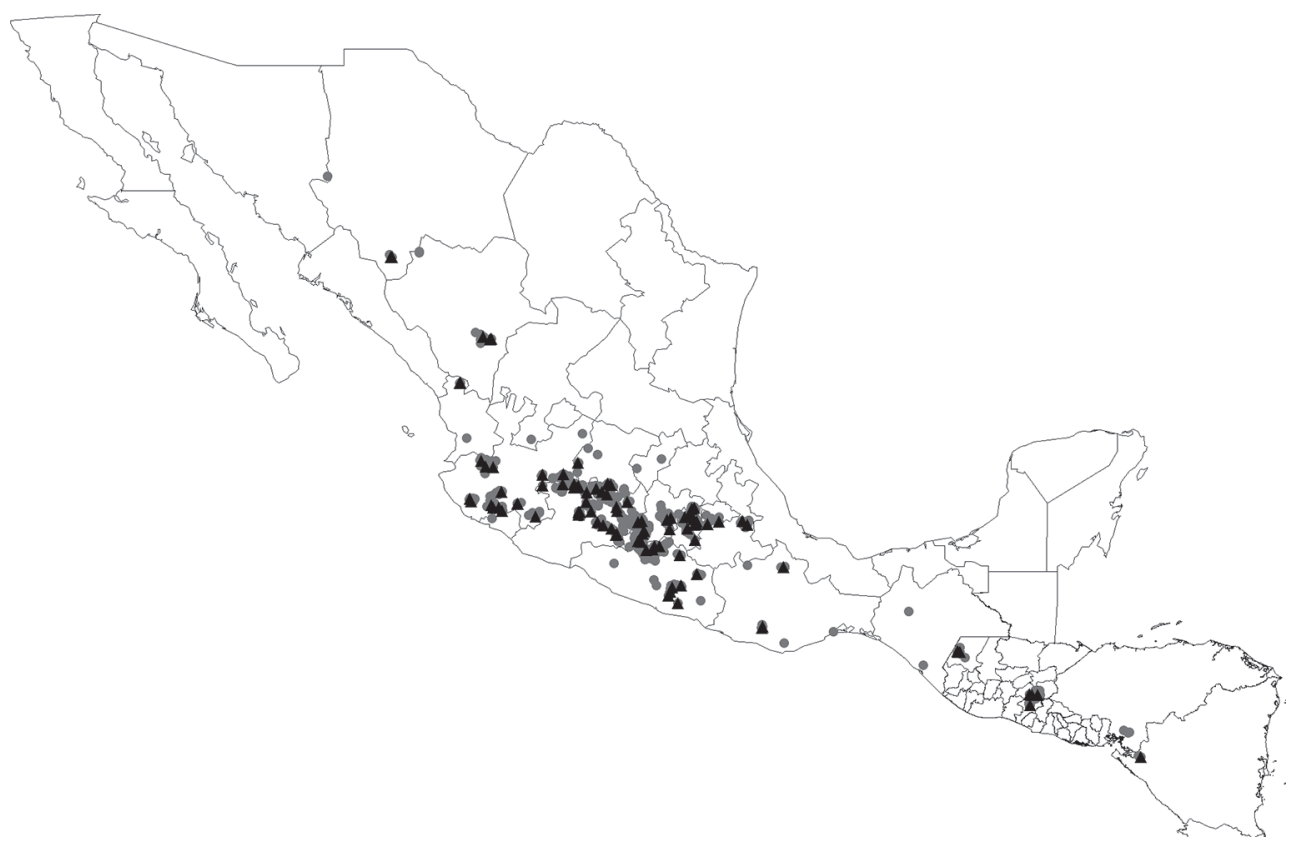

Figura 1. Distribución geográfica de las accesiones utilizadas en este estudio (los círculos grises representan la distribución conocida del teocintle y los triángulos negros las accesiones utilizadas).

dio anual; Temperatura promedio mayo-octubre; Oscilación térmica mayo-octubre (OTO); Temperatura diurna media anual; Temperatura diurna mayo-octubre; Temperatura nocturna media anual; Temperatura nocturna; Precipitación acumulada anual (PMA); Precipitación mes más húmedo; Fotoperiodo promedio mayo-octubre (FMO); Fotoperiodo promedio Noviembre-Abril; Fotoperiodo mínimo en el año; Precipitación pluvial mayo-octubre; Índice de humedad promedio anual (IHA); y Índice de humedad mayo-octubre. Los índices de humedad se definen como la relación entre precipitación anual y evapotranspiración potencial. Para cada taxon se determinaron intervalos climáticos, los cuales fueron establecidos con base en los valores máximos y mínimos para cada variable.

Descriptores morfológicos y fisiológicos

De cada población de teocintle se establecieron cuatro individuos en condiciones de invernadero. Los surcos estuvieron separados $80 \mathrm{~cm}$ y las plantas se espaciaron $50 \mathrm{~cm}$. La siembra se llevó a cabo el 15 de junio de 2011. Se aplicaron riegos semanales hasta la madurez y se fertilizó con un tratamiento equivalente a 
$120 \mathrm{~kg}$ de nitrógeno, $80 \mathrm{~kg}$ de fósforo y $80 \mathrm{~kg}$ de potasio por ha. No se aplicaron insecticidas ni herbicidas.

Para cada una de las cuatro plantas de cada población de teocintle, se midieron 18 caracteres morfológicos y fisiológicos de acuerdo con las descripciones de Doebley (1983a) y Sánchez et al. (1998). Los caracteres registrados corresponden a los que han mostrado mayor repetibilidad y menor sesgo debido a efectos ambientales e interacción genotipo ambiente (Sánchez et al.,1998) y fueron los siguientes:

1) Caracteres vegetativos de planta: Altura de planta (APL) medida en $\mathrm{cm}$, Número de hijos (HIJ); Número de hojas por planta (HOJ); Longitud de hoja (LHO) medida en cm; Días a floración masculina (DFM) obtenida como el número de días de la siembra a la liberación de polen; Días a floración femenina (DFF) registrada como el número de días de la siembra a la aparición de los estigmas; y Área foliar (AFO), calculada con base en los valores del número de hojas, largo y ancho de hoja y expresada en $\mathrm{cm}^{2}$;

2) Caracteres de espiga: Número de ramas de la espiga (RES); Longitud de la rama central espiga (LCE) reportado en $\mathrm{cm}$; Longitud de la parte ramificada (LPR) en cm; y Longitud del pedúnculo de la espiga (PED) medidos en cm;

3) Caracteres de espiguilla: Ancho de espiguilla (ASP) registrado en mm; y Longitud de espiguilla (LSP) medida en mm;

4) Caracteres de grano: Número de granos por mazorca (GRA); y Peso de 100 granos (P100S) medido en $\mathrm{g}$;

5) Caracteres de estigma: Longitud de estigma (LST) expresada en cm; Ancho de estigma (AST) reportado en mm; y Número de tricomas (TRI).

Para la medición de caracteres de espiguilla y estigma se utilizó un estereomicroscopio binocular Zeiss Stemi 2000c, equipado con cámara Axio Cam Cc1 y el software Axiovision 4.8.

Análisis estadísticos

Se llevaron a cabo análisis de agrupamiento y de componentes principales para los datos morfológicos, para las variables climatológicas y para el total de variables; se realizó una estandarización a media cero y varianza 1; se calcularon distancias euclidianas; y se hizo el análisis de agrupamiento utilizando el método de incremento en la suma de cuadrados.

Para estimar el número óptimo de grupos se usó la validación propuesta por Wishart (2006) contenida en el programa Clustan Graphics V8, utilizando 10000 re- 
peticiones. El método compara el agrupamiento obtenido a partir de la información original con los de aquel generado por permutación aleatoria de los datos.

El análisis de componentes principales se realizó con toda la información disponible usando el Sistema de Análisis Estadístico (SAS Institute Inc., 2004). Los resultados se presentan en una gráfica Biplot que visualiza tanto las relaciones entre accesiones como entre las variables. La correlación entre las matrices de similitud de caracteres morfológicos y fisiológicos con los datos climatológicos se evaluó con base en la prueba de Mantel, la cual calcula la significancia estadística y se efectúa por aleatorización en los elementos de una de las matrices, obteniendo un valor de Z (Manly, 1997). La prueba de permutaciones se llevó a cabo con base en el módulo MXCOMP de NTSYS versión 2.21 (Rohlf, 2009). Las relaciones entre los caracteres morfológicos y fisiológicos con los climatológicos se investigaron usando análisis de correlación canónica (Anónimo, 2004).

\section{RESULTADOS}

En el Apéndice se presenta la información sobre la localización geográfica de las accesiones usadas, su clasificación en razas y especies y las claves usadas en los dendrogramas de las figuras 2, 3 y 4 . En dicho cuadro se observa que el teocintle estudiado proviene de 14 estados tanto de México como de Guatemala y Nicaragua. La raza Chalco se encuentra en las áreas de mayor altitud (2200 a $2670 \mathrm{~m}$ ) mientras que la elevación menor corresponde a Zea nicaraguensis con 15 m s.n.m. La raza Balsas es un grupo cuyas poblaciones se registran a altitudes entre 635 y 1272 m; mientras que la raza Mesa Central tiene un rango de 1550 a 2186 m s.n.m. Los teocintles de la sección Luxuriantes poseen una amplia área de distribución, desde Nicaragua a una latitud cercana a $13^{\circ} \mathrm{N}$ hasta Nayarit a casi $23^{\circ} \mathrm{N}$ y altitudes de 15 a $2250 \mathrm{~m}$.

En el Cuadro 1 se muestran las medias así como los valores máximos, mínimos, desviación estándar y el coeficiente de variación para 18 caracteres morfológicos y 21 variables climatológicas. Con base en los rangos observados, es muy notoria la gran variación existente en el teocintle; la mayor se presenta en los aspectos morfológicos, especialmente en el número de ramas de la espiga, de 1 a 154, con Coeficiente de Variación (CV) de 80\%. El número de hijos tiene un intervalo de cero a $25(\mathrm{CV}=73.6)$, mientras que el de los días a floración masculina es de 45 a $302(\mathrm{CV}=44)$. Se observó una variación similar para la cantidad de tricomas y la longitud de la parte ramificada de la espiga. Los menores valores fueron los de es- 
Cuadro 1. Medias, valores máximo y mínimo, desviaciones estándar y coeficientes de variación de variables morfológicas y climatológicas del teocintle.

\begin{tabular}{|c|c|c|c|c|c|}
\hline Variable & Media & $\begin{array}{l}\text { Valor } \\
\text { mínimo }\end{array}$ & $\begin{array}{c}\text { Valor } \\
\text { máximo }\end{array}$ & $\begin{array}{c}\text { Desviación } \\
\text { estándar }\end{array}$ & $\begin{array}{l}\text { Coeficiente } \\
\text { de variación }\end{array}$ \\
\hline Peso de 100 granos (P100S) & 7.7 & 3.3 & 15.6 & 2.9 & 37.9 \\
\hline Días a floración masculina (DFM) & 94.3 & 44.8 & 302.0 & 41.1 & 43.6 \\
\hline Días a floración femenina (DFF) & 92.0 & 43.8 & 306.0 & 42.0 & 45.6 \\
\hline Número de hijos (HIJ) & 8.8 & 0.0 & 25.5 & 6.5 & 73.6 \\
\hline Número de hojas (HOJ) & 14.2 & 4.8 & 22.0 & 3.7 & 26.4 \\
\hline Longitud de hoja (LHO) & 78.6 & 21.6 & 143.6 & 20.5 & 26.1 \\
\hline Altura de planta (APL) & 305.0 & 69.8 & 454.5 & 91.9 & 30.1 \\
\hline $\begin{array}{l}\text { Número de ramas de la espiga } \\
\text { (RES) }\end{array}$ & 46.1 & 1.0 & 154.0 & 36.7 & 79.6 \\
\hline Long. de la parte ramificada (LPR) & 12.0 & 1.1 & 23.0 & 5.5 & 46.1 \\
\hline $\begin{array}{l}\text { Long. de la rama central esp. } \\
\text { (LCE) }\end{array}$ & 11.9 & 6.6 & 19.9 & 2.8 & 23.8 \\
\hline $\begin{array}{l}\text { Long. del pedúnculo de la esp. } \\
\text { (PED) }\end{array}$ & 20.7 & 7.0 & 38.0 & 6.6 & 31.8 \\
\hline $\begin{array}{l}\text { Núm. de granos por mazorca } \\
\text { (GRA) }\end{array}$ & 8.6 & 5.3 & 13.7 & 1.7 & 19.8 \\
\hline Área foliar (AFO) & 350.5 & 18.0 & 649.6 & 120.6 & 34.4 \\
\hline Longitud de estigma (LST) & 11.6 & 4.8 & 24.2 & 3.6 & 30.8 \\
\hline Ancho de estigma (AST) & 0.4 & 0.3 & 0.7 & 0.1 & 19.5 \\
\hline Número de tricomas (TRI) & 22.5 & 7.0 & 92.2 & 12.4 & 55.2 \\
\hline Ancho de espiguilla (ASP) & 2.0 & 1.4 & 2.8 & 0.3 & 16.9 \\
\hline Longitud de espiguilla (LSP) & 7.5 & 5.1 & 12.3 & 1.5 & 19.2 \\
\hline Altitud en msnm (ALT) & 1521.5 & 15.0 & 2670.0 & 625.3 & 41.1 \\
\hline Número de días con temp. $>35^{\circ} \mathrm{C}$ & 15.0 & 0.0 & 69.0 & 15.6 & 103.8 \\
\hline $\begin{array}{l}\text { Temp. máxima promedio anual } \\
\text { (TXO) }\end{array}$ & 26.9 & 21.6 & 33.9 & 2.7 & 10.1 \\
\hline Temp. Máxima mayo-octubre & 27.4 & 21.7 & 33.8 & 2.8 & 10.3 \\
\hline Temp. mínima promedio anual & 12.1 & 6.3 & 23.9 & 3.7 & 30.9 \\
\hline Temp. Mínima mayo-octubre & 14.2 & 8.2 & 24.2 & 3.5 & 24.4 \\
\hline Temperatura promedio anual & 19.5 & 13.9 & 28.9 & 3.2 & 16.4 \\
\hline Temp. promedio mayo-octubre & 20.8 & 14.9 & 29.0 & 3.1 & 14.9 \\
\hline $\begin{array}{l}\text { Oscilación térmica mayo-octubre } \\
(\text { OTO })\end{array}$ & 13.3 & 9.6 & 16.7 & 1.2 & 9.2 \\
\hline
\end{tabular}


Cuadro 1. Continuación.

\begin{tabular}{|c|c|c|c|c|c|}
\hline Variable & Media & $\begin{array}{l}\text { Valor } \\
\text { mínimo }\end{array}$ & $\begin{array}{l}\text { Valor } \\
\text { máximo }\end{array}$ & $\begin{array}{c}\text { Desviación } \\
\text { estándar }\end{array}$ & $\begin{array}{l}\text { Coeficiente } \\
\text { de variación }\end{array}$ \\
\hline Temperatura diurna media anual & 23.4 & 18.0 & 31.5 & 2.9 & 12.5 \\
\hline Temperatura diurna mayo-octubre & 24.1 & 18.4 & 31.4 & 3.0 & 12.3 \\
\hline Temperatura nocturna media anual & 15.6 & 9.9 & 26.3 & 3.5 & 22.3 \\
\hline Temperatura nocturna & 17.5 & 11.5 & 26.6 & 3.3 & 18.7 \\
\hline $\begin{array}{l}\text { Precipitación acumulada anual } \\
\text { (PMA) }\end{array}$ & 1051.3 & 466.7 & 3438.7 & 433.3 & 41.2 \\
\hline Precipitación mes más húmedo & 236.2 & 113.4 & 727.1 & 93.3 & 39.5 \\
\hline $\begin{array}{l}\text { Fotoperiodo prom. mayo-octubre } \\
\text { (FMO) }\end{array}$ & 12.6 & 12.4 & 12.8 & 0.1 & 0.5 \\
\hline $\begin{array}{l}\text { Fotoperiodo prom. Noviembre- } \\
\text { Abril }\end{array}$ & 11.5 & 11.2 & 11.6 & 0.1 & 0.6 \\
\hline Fotoperiodo mínimo en el año & 10.9 & 10.4 & 11.3 & 0.1 & 1.3 \\
\hline $\begin{array}{l}\text { Precipitación pluvial mayo- } \\
\text { octubre }\end{array}$ & 972.7 & 424.8 & 3048.2 & 392.5 & 40.4 \\
\hline $\begin{array}{l}\text { Índice de humedad prom. anual } \\
\text { (IHA) }\end{array}$ & 0.6 & 0.3 & 1.9 & 0.2 & 36.9 \\
\hline Índice de humedad mayo-octubre & 1.1 & 0.5 & 3.2 & 0.4 & 37.0 \\
\hline
\end{tabular}

piguilla, granos por mazorca y ancho de estigma con coeficientes de variación inferiores a $20 \%$. Las variables ecológicas mostraron coeficientes de variación menores; sin embargo, se observa una mayor amplitud para dichos valores. El número de días con temperaturas mayores de $35{ }^{\circ} \mathrm{C}$ fue de cero a $69(\mathrm{CV}=104)$, la precipitación anual acumulada varió de 467 a $3439 \mathrm{~mm}(\mathrm{CV}=41)$, y la altitud del sitio de colecta, asociada con las temperaturas, registró un intervalo de 15 a 2670 m s.n.m. $(\mathrm{CV}=41)$. Las variables relacionadas con el fotoperiodo fueron los que mostraron desviaciones estándar y CV inferiores a uno.

Análisis de agrupamiento

Los resultados de los análisis de agrupamiento de las 95 colecciones de teocintle se presentan en forma de dendrogramas para 18 caracteres morfológicos, 21 variables climatológicas y para todas en conjunto. En la Figura 2 el agrupamiento con aspectos morfológicos identificó siete sectores con base en el método de validación de Clustan Graphics; éstos se pueden organizar en tres grandes secciones. La sección 1, de la parte superior del dendrograma, está constituida por todas las pobla- 


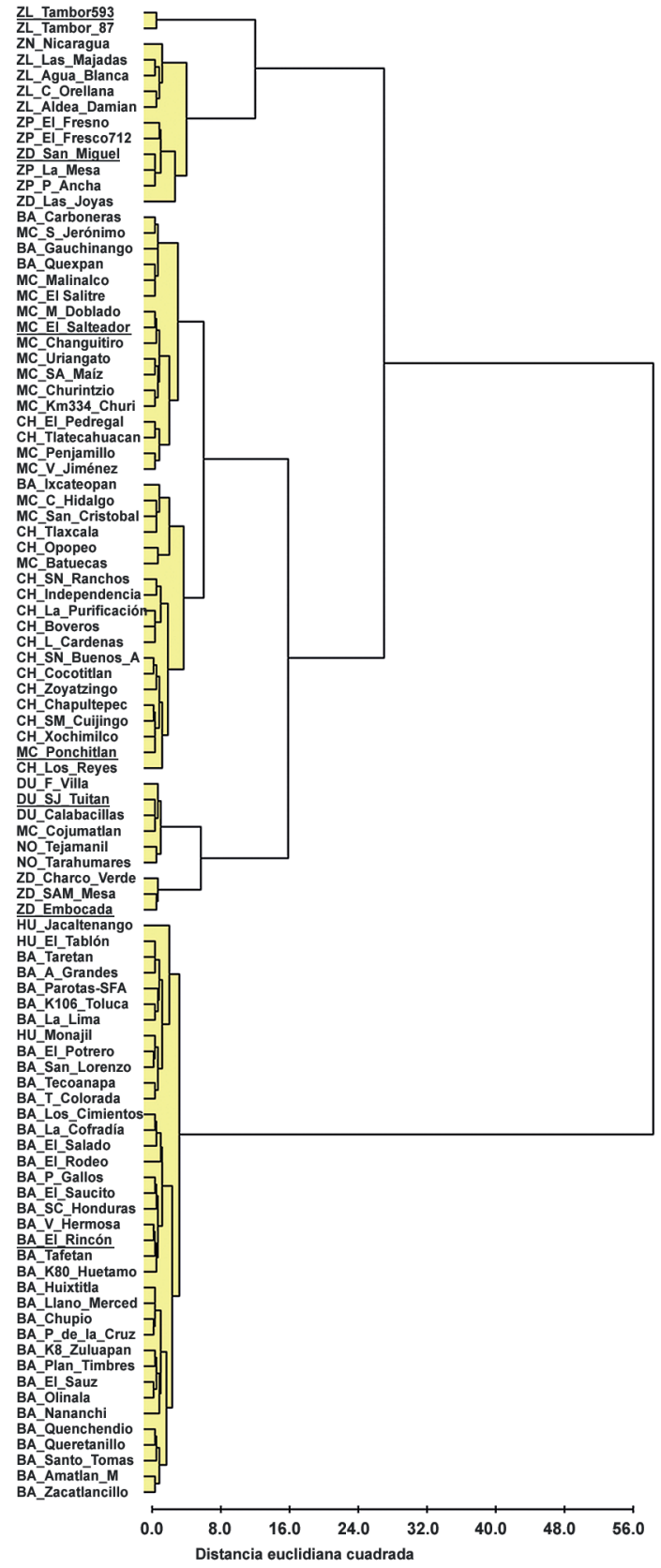

Fig. 2. Análisis de agrupamiento de 95 poblaciones de teocintle con base en 18 caracteres morfológicos (Claves para las accesiones indicadas en el Cuadro 1). 
ciones de la sección Luxuriantes (excepto Zea diploperennis de Nayarit). El primer subgrupo 1A corresponde a Zea luxurians de Oaxaca, el subgrupo 1B incluye a Zea nicaraguensis, Zea luxurians de Guatemala, Zea perennis (Jalisco y Michoacán) y Zea diploperennis de Jalisco. La sección 2 está compuesta casi exclusivamente por Zea mays subsp. mexicana y Zea diploperennis de Nayarit; el subgrupo 2A incluye la mayor parte de la raza Mesa Central; el 2B involucra casi exclusivamente a la raza Chalco; el 2C a Durango y Nobogame, mientras que el 2D incluye al teocintle perenne diploide de Nayarit. Por su parte, la sección 3 incluye prácticamente todas las muestras de Zea mays subsp. parviglumis y las de Zea mays subsp. huehuetenangensis. Cabe señalar que algunas colectas de las razas Balsas tienden a ser similares a la subsp. mexicana, como son los casos de Ixcateopan, Guerrero y otras del área occidente de Jalisco (Carboneras, Gauchinango y Quexpan).

En la Figura 3 el análisis de agrupamiento de acuerdo con las 21 variables climatológicas identificó ocho conjuntos; éstos se pueden organizar en dos grandes secciones. La sección 1, que se encuentra en la parte superior del dendrograma, está compuesta por Zea luxurians de Arroyo Tambor en Oaxaca (1A); el subgrupo 1B está conformado por Zea nicaraguensis, dos poblaciones del sur del estado de Guerrero (Tecoanapa y Tierra Colorada) y dos del área de Villa Purificación, Jalisco; por su parte, el grupo $1 \mathrm{C}$ consiste de accesiones de la raza Balsas colectadas en el sur del estado de México, este de Michoacán, Oaxaca y región este-centro del estado de Guerrero.

La sección 2 incluye cuatro divisiones: en el subgrupo 2A están los teocintles perennes de Jalisco, una colecta de la raza Huehuetenango (Jacaltenango), prácticamente toda la raza Mesa Central y poblaciones clasificadas inicialmente como Balsas y provenientes de zonas de altitudes de 1700 a $1850 \mathrm{~m}$ (Malinalco, Estado de México; Ixcateopan, Guerrero; y Amatlán, Morelos). El subgrupo 2B está muy bien definido e incluye todas las muestras de la raza Chalco y dos de la Mesa Central. El 2C involucra el teocintle perenne tetraploide de Ziracuaretiro, Michoacán, poblaciones de la raza Balsas de altitudes cercanas a $1200 \mathrm{~m}$ y dos de Mesa Central. Finalmente, el 2D está constituido por las variantes precoces de la zona norte de México: raza Nobogame de Chihuahua, raza Durango y Zea diploperennis de Huajicori, Nayarit.

En la Figura 4 se presenta el dendrograma correspondiente al análisis en función de caracteres morfológicos y variables climáticas, el cual identificó ocho grupos que pueden, a su vez, reunirse en dos grandes secciones.

La sección 1 incluye todas las poblaciones de Zea mays subsp. parviglumis, Zea mays subsp. huehuetenangensis, Zea nicaraguensis y Zea luxurians. Zea luxurians de Oaxaca (1A), Zea nicaraguensis y Zea luxurians de Guatema- 


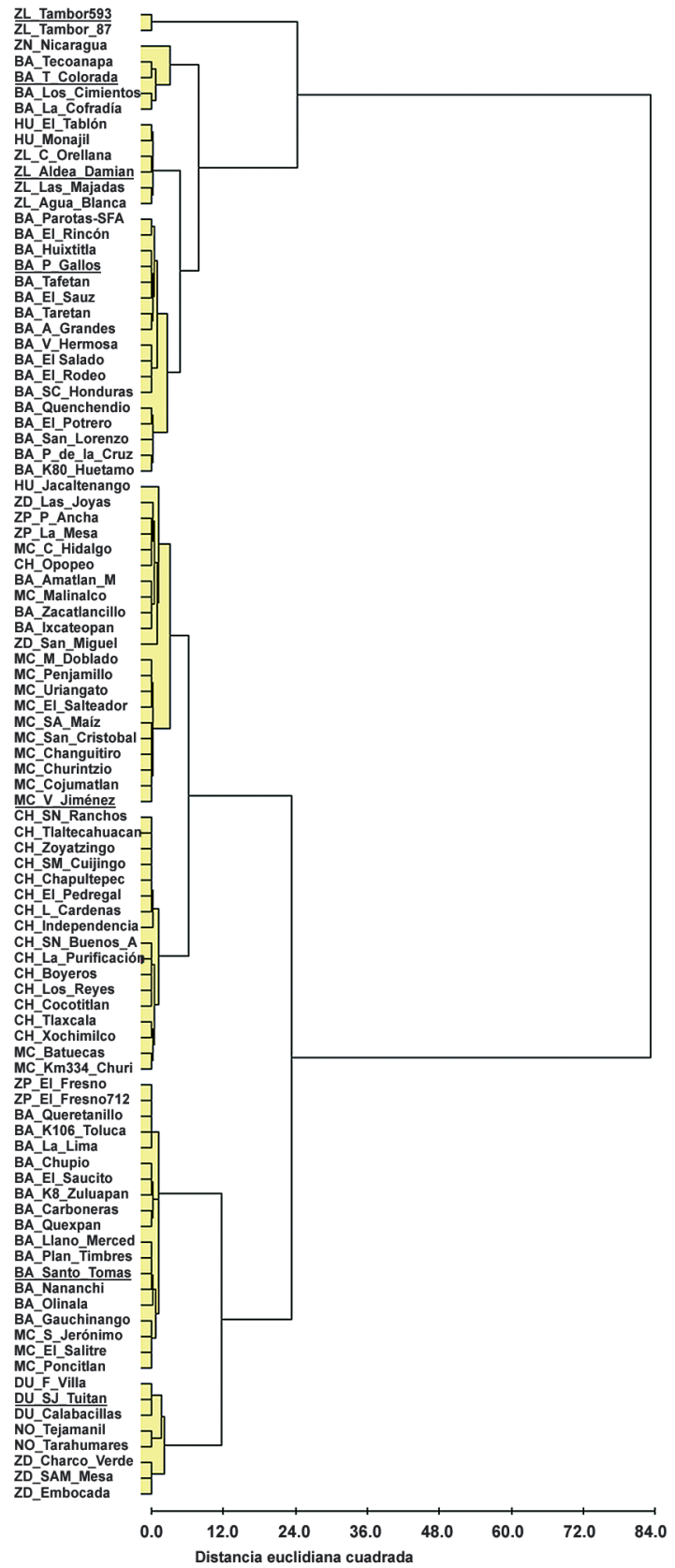

Fig. 3. Análisis de agrupamiento de 95 poblaciones de teocintle con base en 21 variables climatológicas (Claves para las accesiones indicadas en el Cuadro 1). 
Torres Peña et al.: Relaciones entre poblaciones de teocintle (Zea spp.)

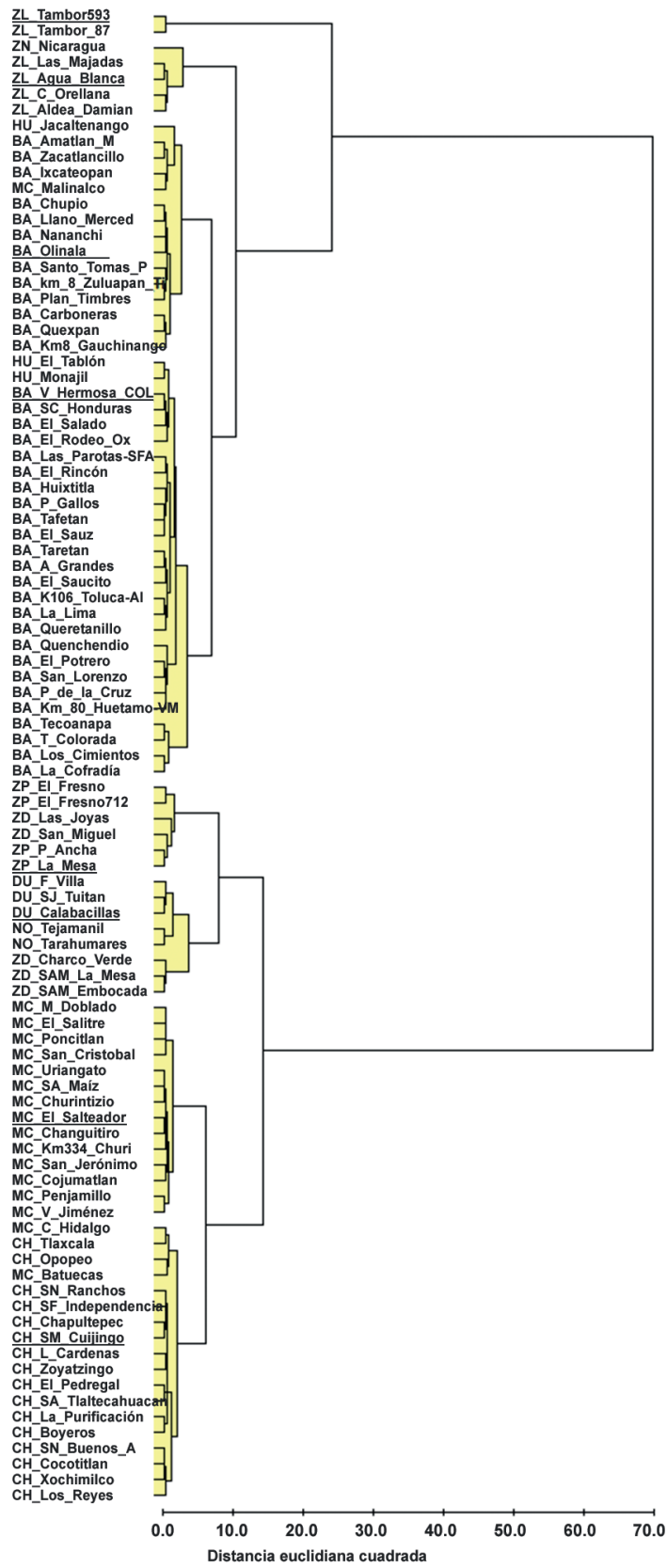

Fig. 4. Análisis de agrupamiento de 95 poblaciones de teocintle con base en 39 variables morfológicas y climatológicas (Claves para las accesiones indicadas en el Apéndice). 
la (1B) son las especies más diferenciadas de esta sección. El subgrupo 1C está formado por poblaciones de las razas Huehuetenango, Balsas y Mesa Central, distribuidas en áreas de altitudes intermedias, mientras que el 1D está constituido por las razas Huehuetenango y Balsas de elevaciones bajas. La sección 2 incluye todos los teocintles perennes y casi la totalidad de Zea mays subsp. mexicana. El subgrupo 2A involucra los teocintles tetraploides y Zea diploperennis de la Sierra de Manantlán, Jalisco; el subgrupo 2B está integrado por las poblaciones precoces de las razas Nobogame de Chihuahua, Durango y Zea diploperennis de Huajicori, Nayarit. El subgrupo 2C consiste casi exclusivamente de la raza Mesa Central, mientras que el 2D está integrado por componentes de la raza Chalco.

Con la finalidad de determinar la correlación entre las matrices de similitud para los caracteres morfológicos y fisiológicos y las variables climáticas, se calculó el valor del estadístico normalizado $Z$ de acuerdo con la prueba de Mantel, el cual fue 0.6109 . La probabilidad $(Z$ de la prueba de aleatorización $\geq Z$ observado $)=$ 0.0001; es decir, existe un buen nivel de concordancia entre los valores de similitudes calculados con las dos bases de datos.

Por su parte, los primeros cinco coeficientes de correlación canónica entre caracteres morfológicos y climatológicos fueron significativos $(\mathrm{P}<0.001)$, explicando $92 \%$ de la variación total en la morfología y climatología con 50, 24 y 9\% para los tres primeros componentes, respectivamente. Las magnitudes de los cinco coeficientes de correlación canónica de mayor importancia para explicar la expresión multivariada de planta en las dos primeras dimensiones son las de las temperaturas. Los caracteres mayormente influenciados por las variables climáticas son días a floración masculina y femenina $(\mathrm{DFM}=0.91, \mathrm{DFF}=0.91)$ y altura de planta $=0.8$; en menor proporción se encuentran número de hojas $=-0.76$, longitud de la hoja (LHO) $=0.58$, longitud de espiguilla $(\mathrm{LSP})=0.68 \mathrm{y}$ ancho de espiguilla $(\mathrm{ASP})=0.59 \mathrm{y}$ peso de 100 semillas $(\mathrm{P} 100 \mathrm{~S})=0.55$.

Componentes principales

Las relaciones entre las 95 poblaciones de teocintle se resumen con base en el análisis de componentes principales. La primera dimensión contribuye a explicar $50.2 \%$, la segunda $15 \%$ y la tercera $12 \%$ de la variación total, respectivamente.

El Componente 1 (CP1) involucra en mayor grado días a floración masculina y femenina, número de hijos y el de hojas por planta así como altitud del sitio de colecta y todas las variables asociadas a la temperatura. El Componente 2 está explicado mayormente por ramas de la espiga, longitud de la parte ramificada, tamaño 
de espiguilla, altura de planta y área foliar así como lo relacionado con precipitación pluvial, índices de humedad y fotoperiodo.

Es importante mencionar que el análisis de componentes principales detectó grupos de variables altamente correlacionadas. Por lo tanto los resultados que se presentan en la Figura 5 incluirán únicamente aspectos representativos de la variación estudiada. La gráfica Biplot de la Figura 5 ilustra las relaciones entre las diferentes poblaciones y, al mismo tiempo, las características que definen los grupos. Como complemento a la Figura 5, en el Cuadro 2 se presentan los promedios por raza para todos los caracteres estudiados.

La dimensión 1 permite separar las poblaciones de Zea mays subsp. mexicana (razas Chalco, Mesa Central, Durango y Nobogame) con valores negativos, de las de Zea mays subsp. parviglumis (raza Balsas), Zea luxurians y Zea nicaraguensis

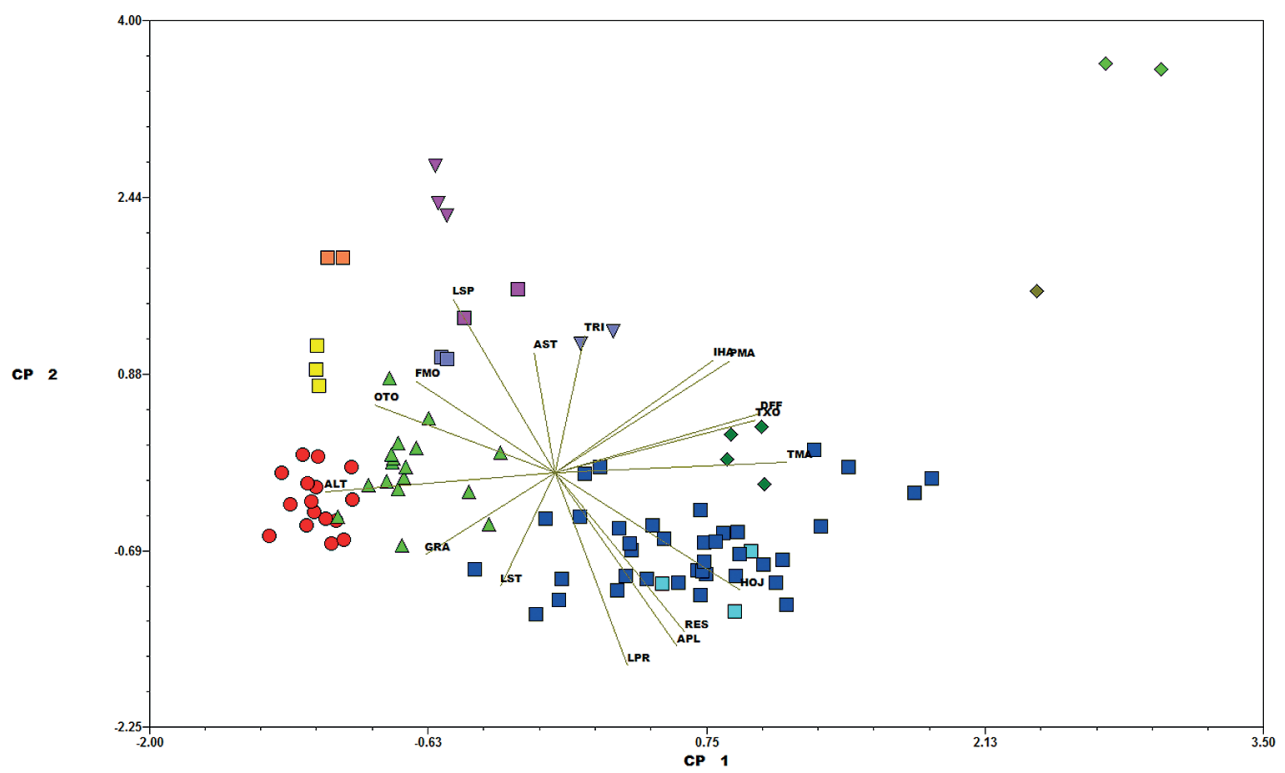

Fig. 5. Gráfica Biplot de 95 poblaciones de teocintle y vectores de variables morfológicas

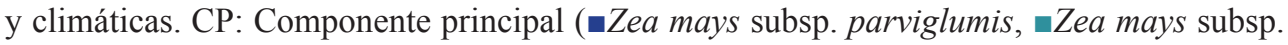
huehuetenangensis, Zea mays subsp. mexicana raza Durango, $₫$ Zea mays subsp. mexicana raza Nobogame, •Zea mays subsp. mexicana raza Chalco, $\Delta$ Zea mays subsp. mexicana raza Mesa Central, Zea nicaraguensis, Zea luxurians-Guatemala, Zea luxurians-Oaxaca, -Zea diploperennis-Jalisco, $\mathbf{\nabla}$ Zea diploperennis-Nayarit, $\mathbf{Z}$ Zea perennis-Jalisco, $\mathbf{\nabla}$ Zea perennis-Michoacán). 
Acta Botanica Mexicana 111: 17-45 (2015)

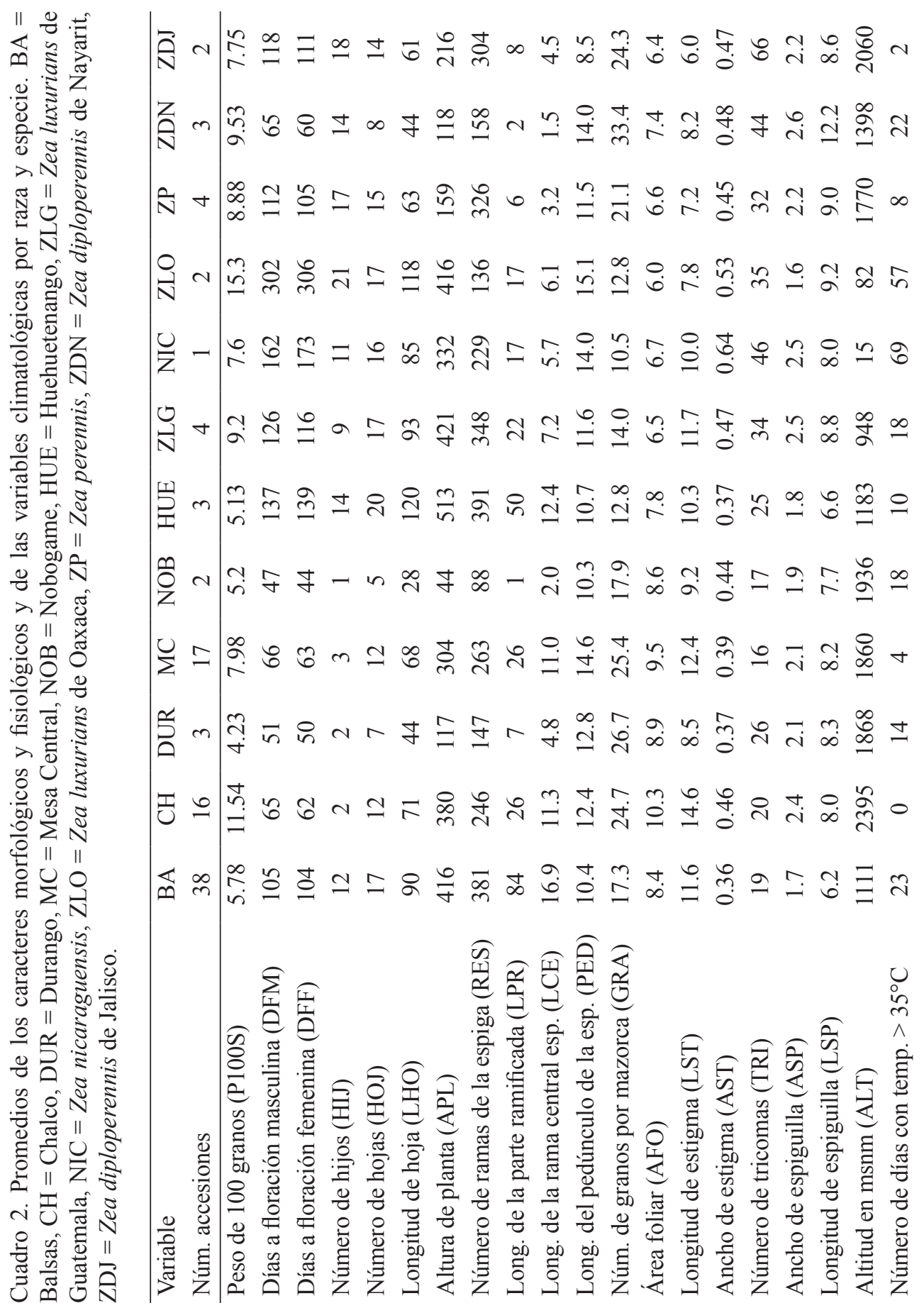


Torres Peña et al.: Relaciones entre poblaciones de teocintle (Zea spp.)

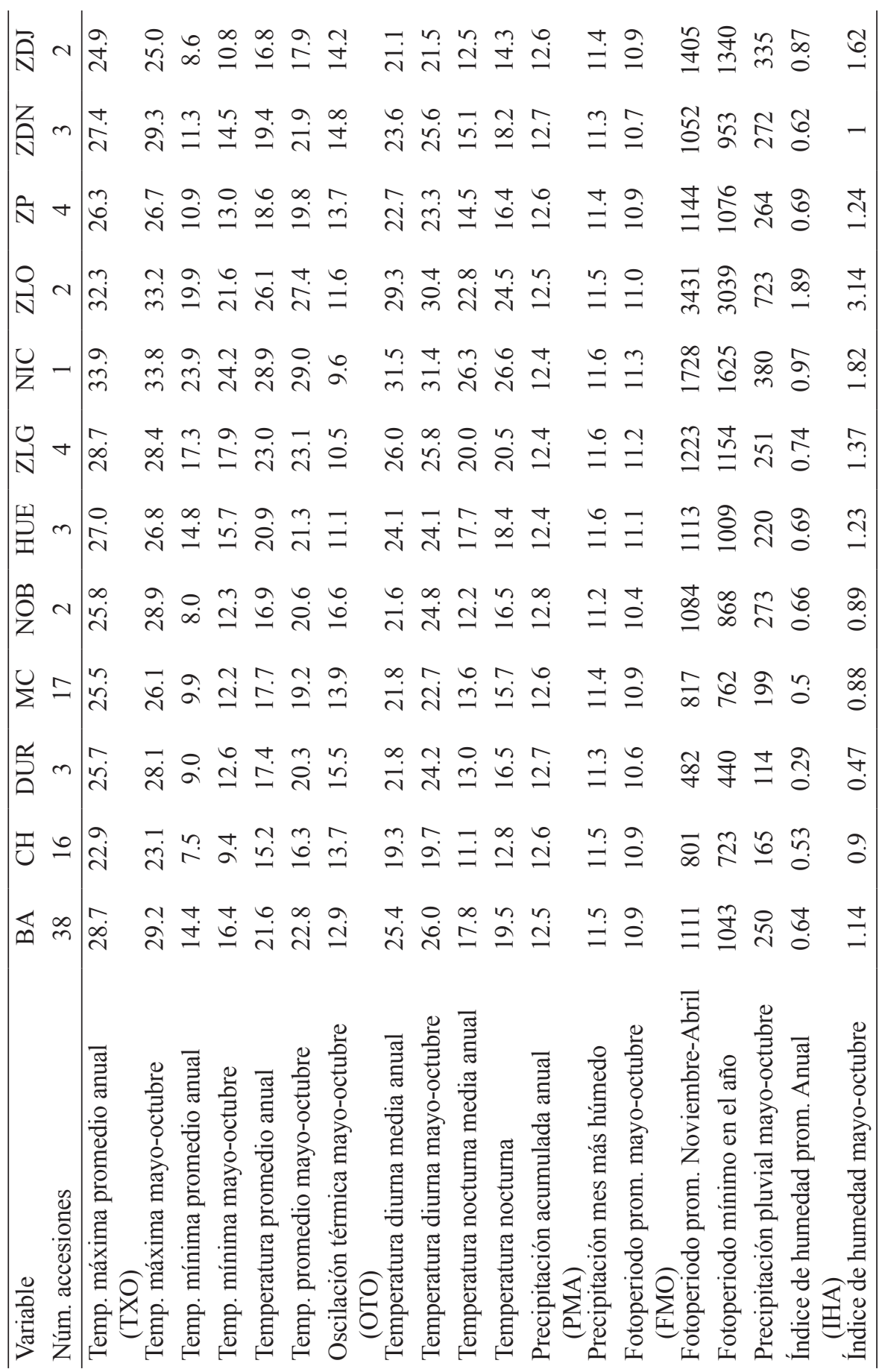


(valores positivos). El segundo componente separa los teocintles mexicanos anuales (excepto Nobogame) de los perennes, Zea luxurians de Oaxaca y Zea nicaraguensis. En la Figura 5 se observa una diferenciación entre Chalco y Mesa Central, mientras que Durango aparece en situación intermedia entre Nobogame y Mesa Central.

Por otra parte, el CP1 separa el teocintle tetraploide de Michoacán del de Jalisco, mientras que el Componente 2 permite diferenciar el perenne diploide de Nayarit del de Jalisco. Es notorio que Zea mays subsp. huehuetenangensis no se separa con suficiente claridad de Zea mays subsp. parviglumis, mientras que Zea luxurians de Guatemala es similar a algunas poblaciones de Zea mays subsp. parviglumis, provenientes del sur del estado de Guerrero y del área de Villa Purificación, Jalisco.

Las diferencias entre grupos de poblaciones pueden explicarse tanto por aspectos morfológicos como por características climatológicas del sitio de colecta. Por ejemplo la raza Chalco es precoz y se adapta a sitios de gran altitud en donde predominan las menores temperaturas (Cuadro 2). Zea luxurians de Oaxaca y Zea nicaraguensis son los teocintles más tardíos y se colectaron en las regiones cercanas al mar con altas temperaturas y alta humedad. De manera general se caracterizan por presentar los mayores valores del índice de humedad promedio, precipitación pluvial acumulada anual, número de días a floración femenina, temperatura promedio para el periodo mayo-octubre y menor número de granos.

Gran parte de las poblaciones de las razas Balsas y Huehuetenango se caracterizan por los mayores promedios de la longitud de la parte ramificada de la espiga, altura de planta, número total de ramas en la espiga, número de hojas por planta, temperaturas promedio anuales. La oscilación térmica y el fotoperiodo promedio son de los de menor valor. Por su parte, los teocintles perennes tienen las espiguillas más grandes, el mayor número de tricomas en los estigmas y menos ramas de la espiga. Los teocintles perennes diploides de Nayarit y Nobogame registran los fotoperiodos y oscilaciones térmicas más altos.

\section{DISCUSIÓN}

Los estudios taxonómicos recientes del género Zea han tenido dos etapas principales. En primer término se cuenta con los trabajos realizados por G.H. Wilkes, quien propuso la división del teocintle en razas basado en aspectos morfológicos y en gran medida en ecogeográficos (Wilkes, 1967). Posteriormente, en la década de los ochenta del siglo XX, H.H. Iltis y J.F. Doebley (Iltis y Doebley, 1980; Doebley e 
Iltis, 1980; Doebley, 1990) propusieron una división jerárquica de Zea con base en criterios ecológicos y especialmente basada en la morfología de la espiga masculina, considerando que esas estructuras no han sido sujetas a selección.

Desde entonces ha habido muy pocos trabajos para avanzar en el conocimiento de la variación del teocintle (Sánchez et al. 1998; Sánchez et al., 2011), sobre todo teniendo en cuenta que se han colectado nuevas variantes, especialmente en los últimos 15 años. Con el desarrollo de los sistemas de información geográfica, los de posicionamiento global y la depuración de los datos climatológicos mundiales ha sido posible combinar los aspectos ecogeográficos y morfológicos para lograr un mejor entendimiento de los procesos de adaptación a las condiciones ambientales y mayor aproximación en los procesos de clasificación.

En este trabajo se demuestra, tanto por los análisis de agrupamiento, correlación canónica y por la prueba de Mantel, la existencia de gran variación ecológica y geográfica, así como en la morfología y fisiología del teocintle. Su dispersión en Mesoamérica ha dado como resultado la evolución de razas y especies cuyas poblaciones se distribuyen en regiones geográficas cercanas, las cuales tienden a presentar características ecológicas similares. Desde el punto de vista climático destacan la gran influencia de la temperatura y fotoperiodo en definir la adaptación y la gran diferenciación morfológica existente en el teocintle. Al mismo tiempo, los mecanismos de aislamiento han dado como resultado una divergencia evolutiva entre las poblaciones más cercanas geográficamente. Todos los aspectos señalados anteriormente ayudan a explicar las diferencias entre las especies silvestres de Zea.

A pesar de algunas diferencias, los resultados de este estudio son congruentes con trabajos previos (Doebley e Iltis, 1980; Doebley et al., 1984; Sánchez et al., 1998; Sánchez et al., 2011). Además, se mostró que desde el punto de vista morfológico y climatológico, la raza Huehuetenango presenta relación muy cercana con Balsas. De la misma manera Zea nicaraguensis parece más una subunidad de Zea luxurians que una especie diferente como lo señalaron Iltis y Benz (2000).

Desde el punto de vista morfológico, la raza Balsas se ubica de manera compacta en un solo grupo, mientras que se divide en dos unidades cuando se consideran las variables climatológicas y los datos conjuntos. Efectivamente, esta raza ha sido encontrada en el intervalo más amplio de condiciones ambientales. Los datos apoyan la sugerencia de algunos autores que han propuesto dividir este grupo en al menos dos razas (Sánchez et al., 1998; Sánchez, 2011).

También se encontró que existen poblaciones intermedias entre las subespecies mexicana y parviglumis, las cuales han sido difíciles de clasificar, entre las que se encuentran las de Malinalco, Estado de México,Ixcateopan, Guerrero, Quexpan, 
Guachinango y Carboneras de Jalisco. Zea luxurians de Oaxaca tiene algunas características morfológicas que la relacionan con esa misma especie de Guatemala. Sin embargo, sus semillas son de mayor tamaño, presentan latencia muy profunda y además se desarrollan en un ambiente único respecto a humedad y temperatura, lo cual al parecer le ha permitido un alto grado de diferenciación (Sánchez et al., 2011).

Dentro de los perennes, el teocintle diploide de Huajicori, Nayarit, muestra diferencias muy marcadas en cuanto a morfología y fisiología de sus plantas, así como de las características climatológicas del sitio de recolección, con respecto al resto de especies perennes diploides y tetraploides. Estos atributos indican que debería considerarse como una especie distinta.

La gran diversidad morfológica y capacidad de adaptación a condiciones ecológicas especiales son relevantes, dado que representan un gran potencial para el descubrimiento de alelos nuevos, no presentes en el maíz moderno. Los resultados de este trabajo ayudarán a la revisión de la taxonomía del género Zea, a definir áreas potenciales de distribución, a diseñar programas de conservación y a orientar los esfuerzos de mejoramiento genético del maíz.

Por ejemplo Zea luxurians y Zea nicaraguensis, que se distribuyen en áreas con una precipitación pluvial del orden de $2000 \mathrm{~mm}$ anuales poseen genes de resistencia a inundaciones, los cuales les dan la capacidad de formar aerénquima en las raíces (Mano y Omori, 2007; Mano et al., 2009). Se espera que el teocintle de San Felipe Usila, Oaxaca, donde llueve cerca de $4000 \mathrm{~mm}$ anuales, pueda también ser una fuente de alelos para prosperar en situación de inundaciones. Nault (1983) encontró que Zea perennis y Zea diploperennis tienen resistencia a varios virus que atacan al maíz. Por otra parte, una de las pocas fuentes de tolerar a Striga spp., una planta parásita de las raíces del maíz, es Zea diploperennis (Rich y Ejeta, 2008). Se espera que las nuevas variantes descritas por Sánchez et al. (2011) y las consideradas en este estudio puedan representar fuentes importantes de alelos para el mejoramiento del maíz.

\section{CONCLUSIÓN}

El uso combinado de datos morfológicos, fisiológicos y climatológicos, así como los análisis multivariados, es una estrategia que permitió describir la gran complejidad de las relaciones entre las poblaciones de diferentes especies de teocintle y de varias zonas geográficas de México y América Central. De manera especial, los análisis canónicos facilitaron la identificación de la temperatura y el fotoperiodo 
como las variables climáticas de mayor relevancia. Los análisis revelaron patrones morfológicos, fisiológicos y geográficos bien definidos. La raza Balsas mostró la mayor diversidad morfológica y de adaptación, mientras que dentro de la subsp. mexicana existe una clara separación de las razas Chalco, Nobogame, y Durango. Sin embargo, Zea luxurians de Oaxaca se separa del resto de teocintles con la mayor distancia.

Es necesario contar con datos moleculares con una cobertura completa del genoma, para -en conjunto con los datos morfo-fisiológicos y ecogeográficos-definir los límites de especies, subespecies y razas de teocintle. Sin embargo, es posible indicar que Zea nicaraguensis debe considerarse una subespecie de Zea luxurians, mientras que Zea luxurians de Oaxaca y Zea diploperennis de Huajicori, Nayarit son taxa diferentes. Asimismo se apoya la idea de reconocer a Durango como una raza independiente de Mesa Central y dividir Zea mays subsp. parviglumis en al menos dos razas.

\section{LITERATURA CITADA}

Anderson, E. y H. C. Cutler. 1942. Races of Zea mays. I. Their recognition and classification. Ann. Missouri Bot. Gard. 29: 69-88.

Anónimo. 2004. SAS/STAT ${ }^{\circledR} 9.1$ User’s Guide. Cary, NC: SAS Institute Inc. 5121 pp.

Anónimo. 2008. Capital natural de México. Vol. 1. Conocimiento actual de la biodiversidad. Comisión Nacional para el Conocimiento y Uso de la Biodiversidad. México, D.F., México. 620 pp.

Doebley, J. F. 1983a. The maize and teosinte male inflorescence: A numerical taxonomic study. Ann. Missouri Bot. Gard. 70: 32-70.

Doebley, J. F. 1983b. The taxonomy and evolution of Tripsacum and teosinte, the closest relatives of maize. In: Gordon, D. T., J. K. Knoke, L. R. Nault y R. M. Ritter (eds.). Proceedings International Maize Virus Disease Colloquium and Workshop, 2-6 August 1982. The Ohio State University, Columbus, Ohio Agricultural Research and Development Center. Wooster, Ohio, USA. pp. 15-28.

Doebley, J. F. 1990. Molecular systematics of Zea (Graminae). Maydica 35: 143-150.

Doebley, J. F., M. M. Goodman y C. W. Stuber. 1984. Isoenzymatic variation in Zea (Gramineae). Syst. Bot. 9: 203-218.

Doebley, J. F. y H. H. Iltis. 1980. Taxonomy of Zea (Gramineae) I. A subgeneric classification with key to taxa. Amer. J. Bot. 67: 982-993.

Eastman, J. R. 2012. Idrisi Selva Manual. Clark University. Worcester, Massachusetts, USA. $322 \mathrm{pp}$.

Iltis, H. H. y J. F. Doebley. 1980. Taxonomy of Zea (Gramineae). II. Subspecific categories in the Zea mays complex and a generic synopsis. Amer. J. Bot. 67: 994-1004. 
Iltis, H. H. y B. F. Benz. 2000. Zea nicaraguensis (Poaceae), a new teosinte from Pacific coastal Nicaragua. Novon 10: 382-390.

Manly, B. F. J. 1997. Randomization, Bootstrap and Monte Carlo methods in biology. Chapman and Hall. London, UK. 399 pp.

Mano, Y. y F. Omori. 2007. Breeding for flooding tolerant maize using "teosinte" as a germplasm resource. Plant Root 1: 17-21.

Mano, Y., F. Omori, C. H. Loaisiga y R. Mck Bird. 2009. QTL mapping of above-ground adventitious roots during flooding in maize $\mathrm{x}$ teosinte "Zea nicaraguensis" backcross population. Plant Root 3: 3-9.

Nault, L. R. 1983. Origins of leafhopper vectors of maize pathogens in Mesoamerica. In: Gordon, D. T., J. K. Knoke, L. R. Nault and R. M. Ritter (eds.). Proceedings International Maize Virus Disease Colloquium and Workshop, 2-6 August 1982. The Ohio State University, Ohio Agricultural Research and Development Center. Wooster, Ohio, USA. pp. 75-82.

Rich, P. J. y G. Ejeta. 2008. Towards effective resistance to Striga in African maize. Plant Signal Behav. 3(9): 618-621.

Rohlf, F. J. 2009. NTSYSpc: Numeral taxonomy and multivariate analysis system. Ver. 2.2. Exeter Software. Setauket, New York, USA. 42 pp.

Sánchez G., J. J. 2011. Diversidad del maíz y el teocintle. Informe del proyecto: "Recopilación, generación, actualización y análisis de información acerca de la diversidad genética de maíces y sus parientes silvestres en México". Comisión Nacional para el Conocimiento y Uso de la Biodiversidad. México, D.F., México. 98 pp. Consulta 5 de agosto de 2013. (http://www.biodiversidad.gob.mx/genes/proyectoMaices.html).

Sánchez G., J. J., L. De la Cruz L., V. A. Vidal M., J. Ron P., S. Taba, F. Santacruz-Ruvalcaba, S. Sood, J. B. Holland, J. A. Ruíz C., S. Carvajal, F. Aragón C., V. H. Chávez T., M. M. Morales R. y R. Barba-González. 2011. Three new teosintes (Zea spp., Poaceae) from México. Amer. J. Bot. 98 (9): 1537-1548.

Sánchez G., J. J., T. A. Kato Y., M. Aguilar S., J. M. Hernández C., A. López R. y J. A. Ruiz C. 1998. Distribución y caracterización del teocintle. Libro Técnico Núm. 2. Centro de Investigación Regional del Pacífico Centro, Instituto Nacional de Investigaciones Forestales, Agrícolas y Pecuarias. México, D.F., México. 150 pp.

Wilkes, H. G. 1967. Teosinte: the closest relative of maize. The Bussey Institution of Harvard University, USA. 159 pp.

Wishart, D. 2006. Clustan Graphics Primer: A guide to cluster analysis. Clustan Limited. Edinburgh, UK. 67 pp. 
Torres Peña et al.: Relaciones entre poblaciones de teocintle (Zea spp.)

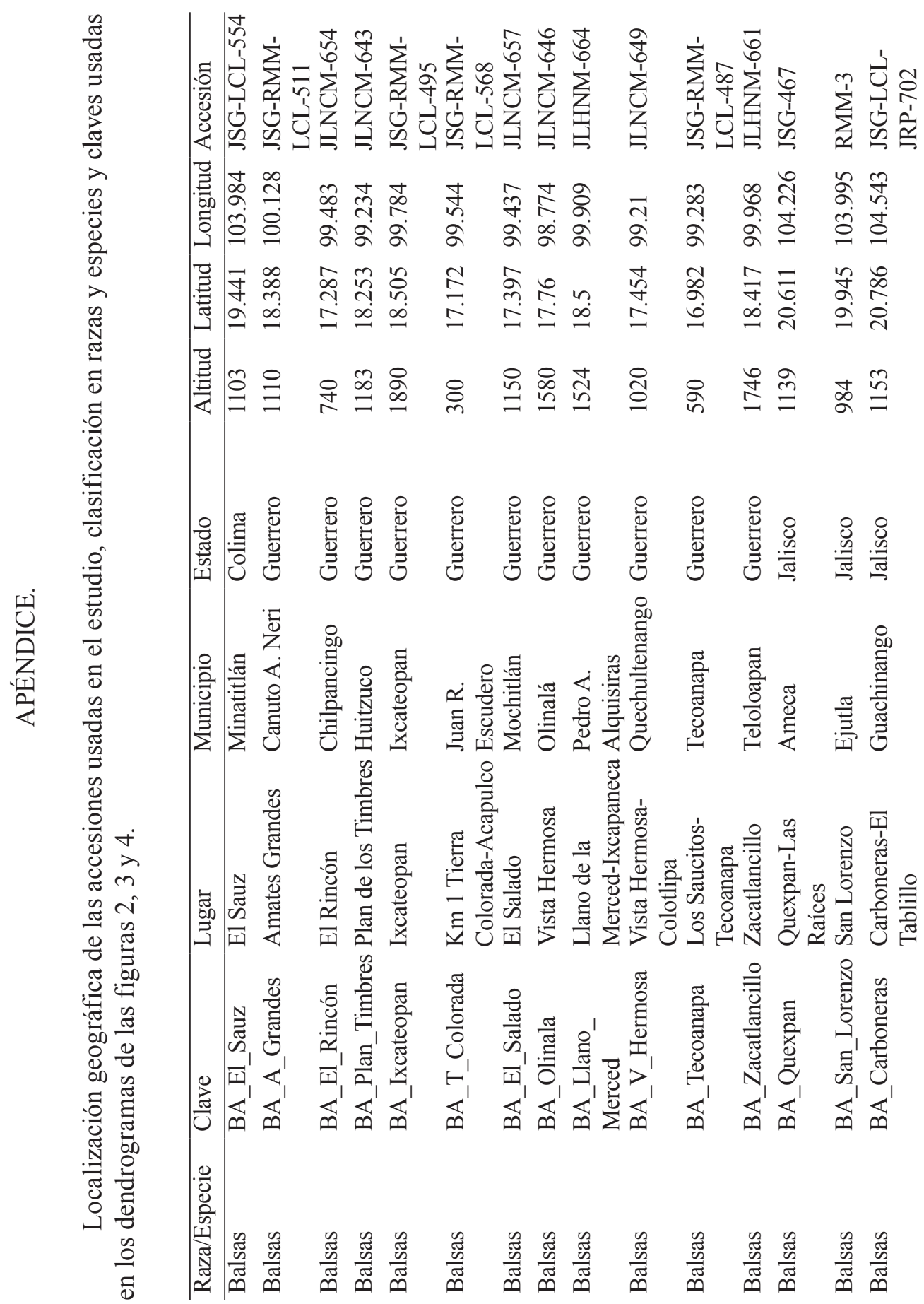


Acta Botanica Mexicana 111: 17-45 (2015)

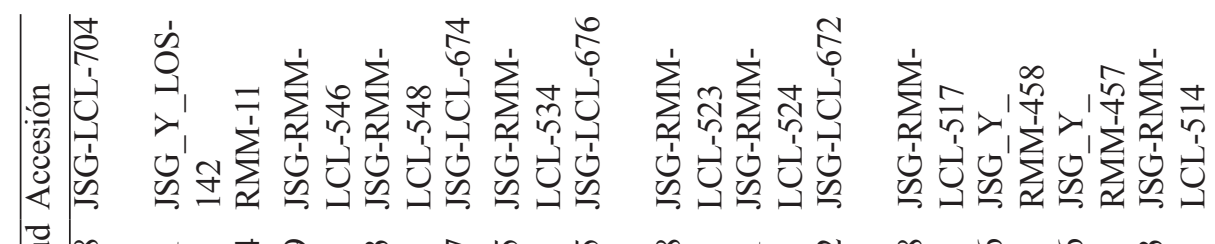

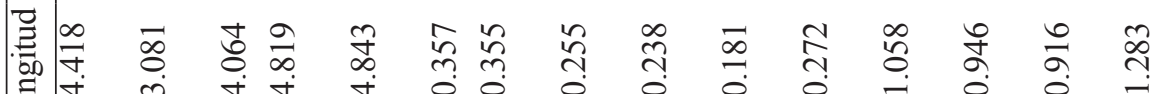

○

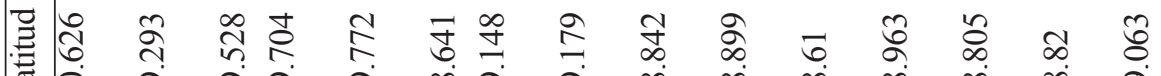

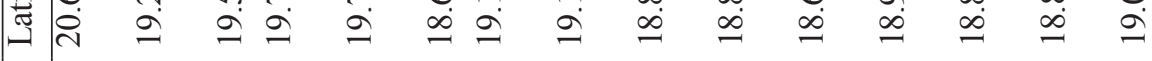

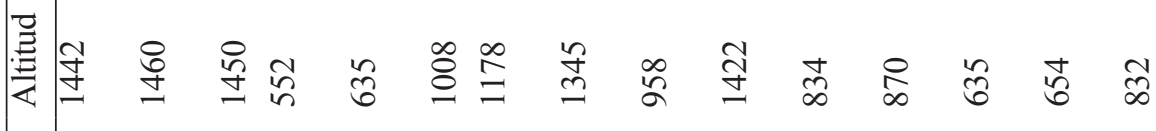

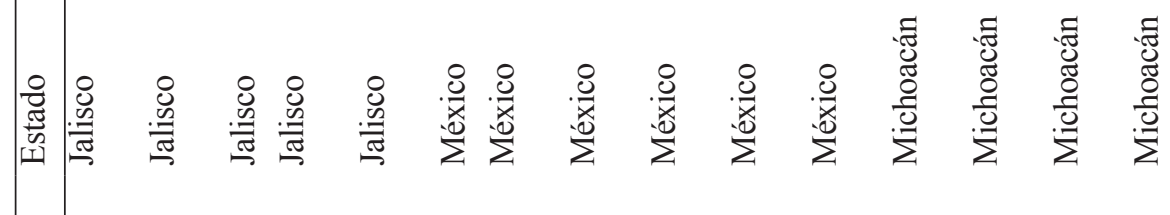

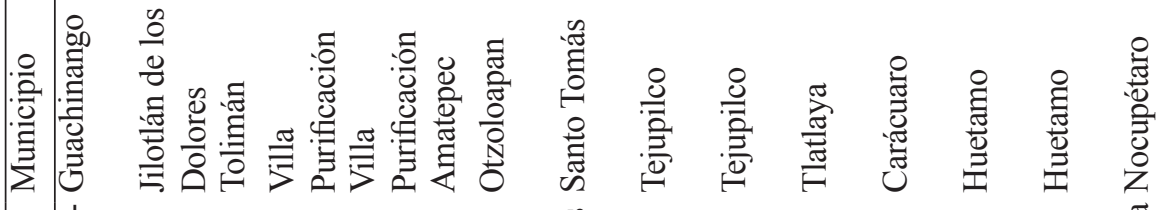

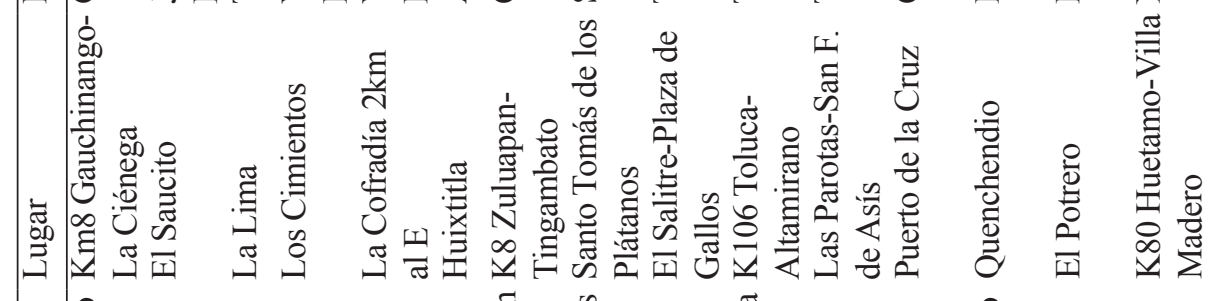

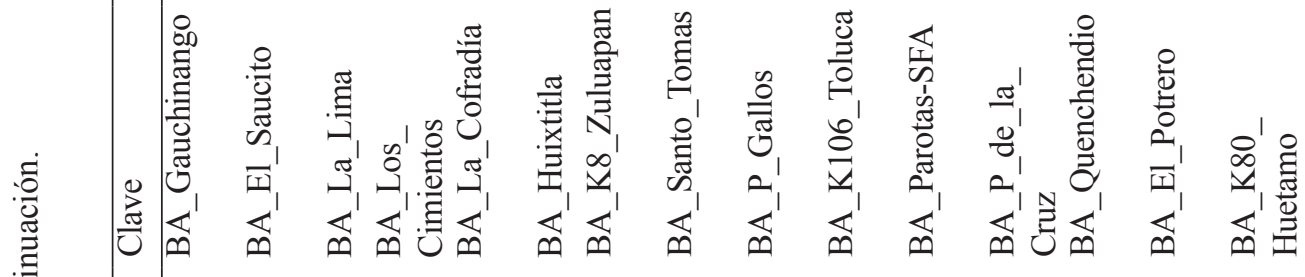

$\frac{0}{8}$

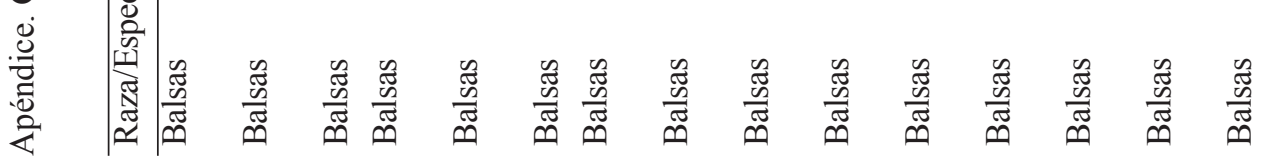


Torres Peña et al.: Relaciones entre poblaciones de teocintle (Zea spp.)

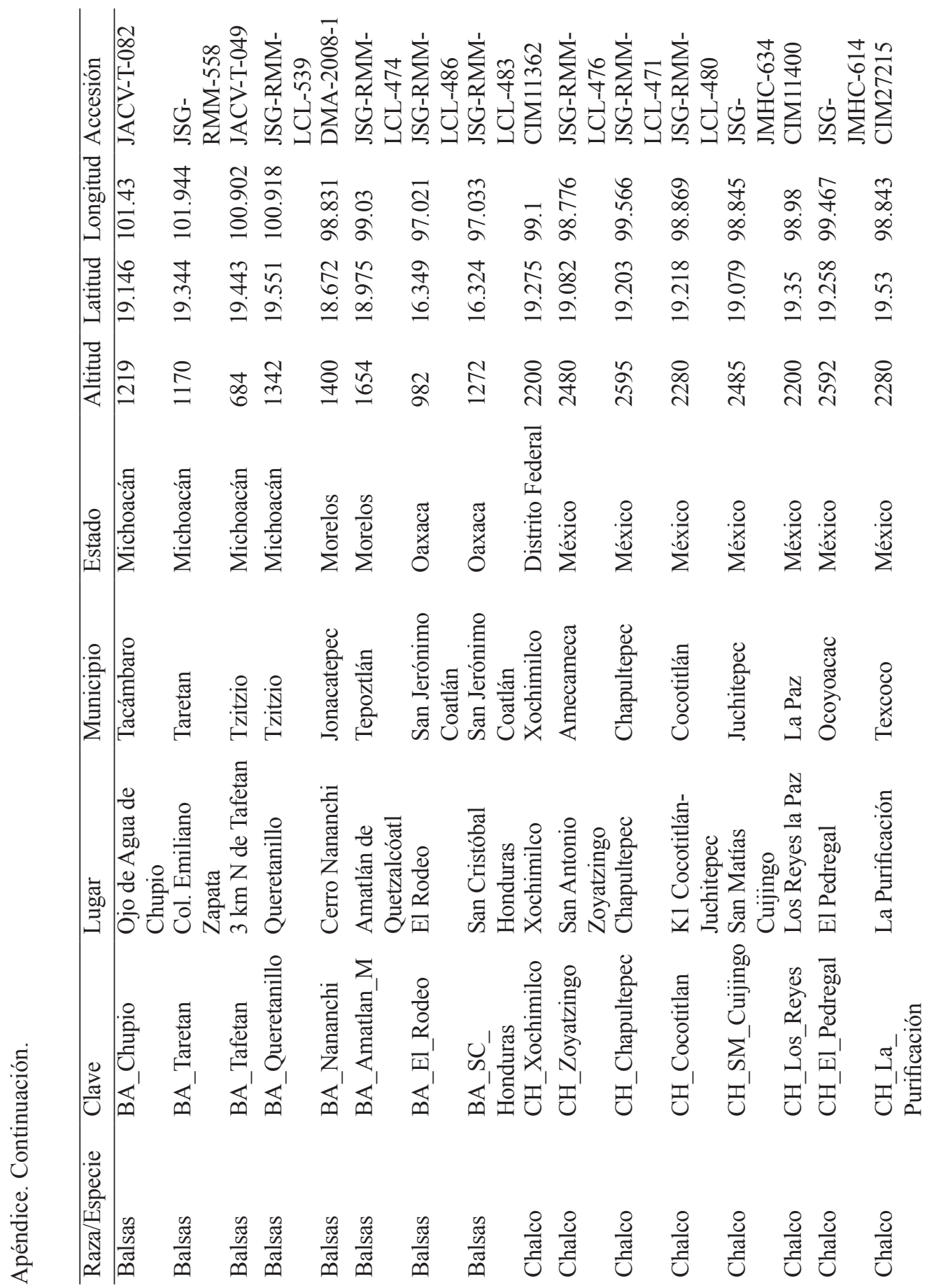


Acta Botanica Mexicana 111: 17-45 (2015)

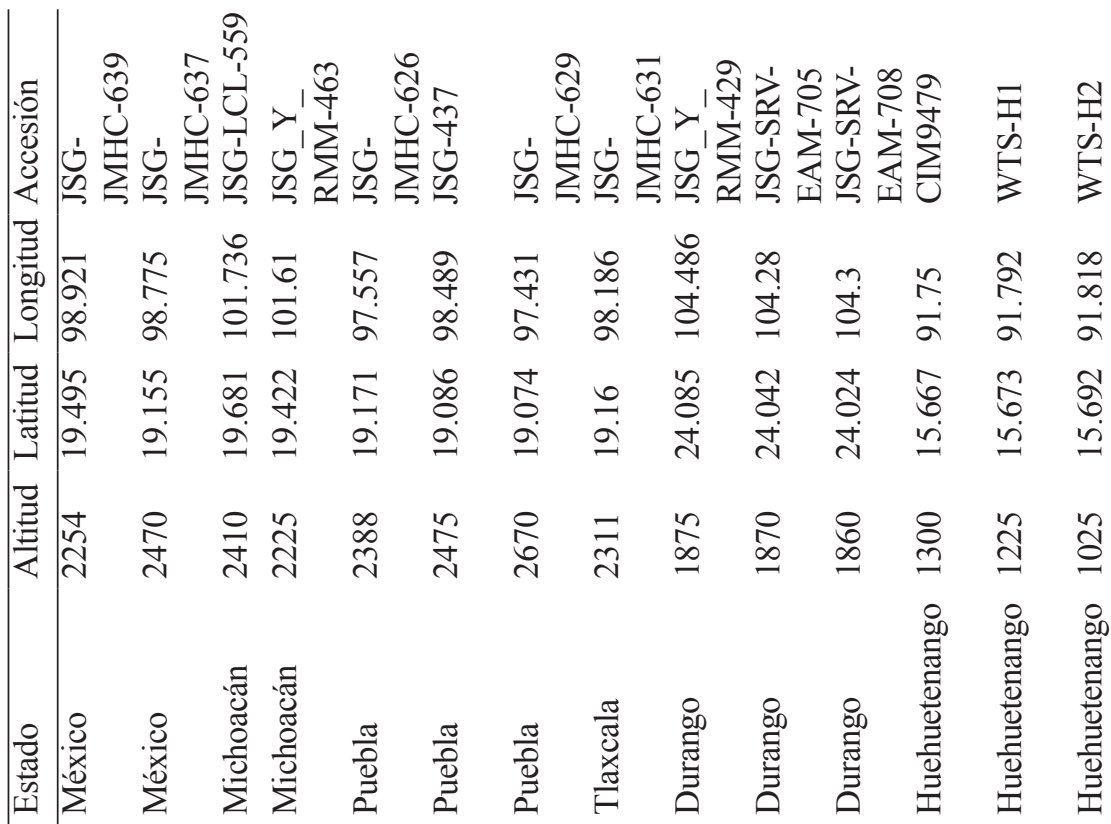

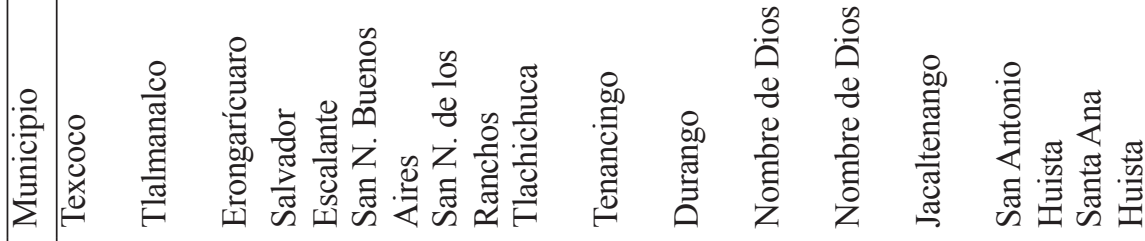

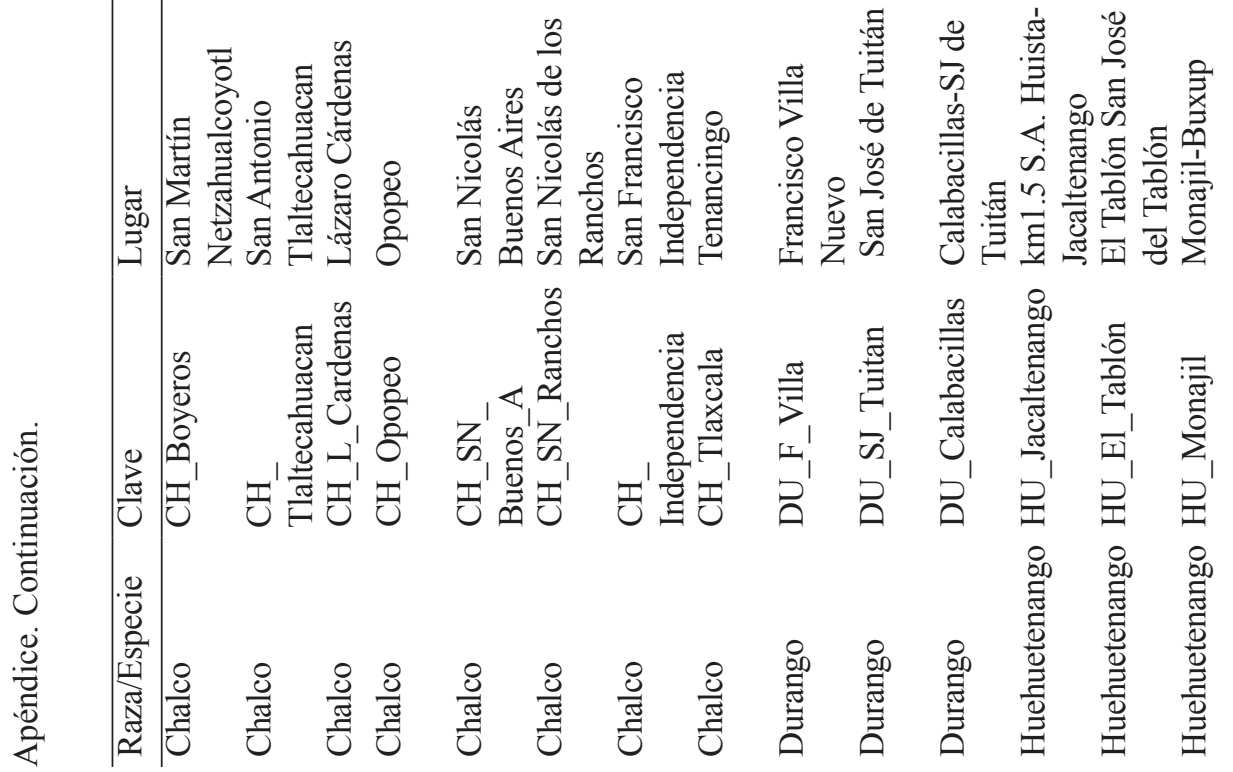


Torres Peña et al.: Relaciones entre poblaciones de teocintle (Zea spp.)

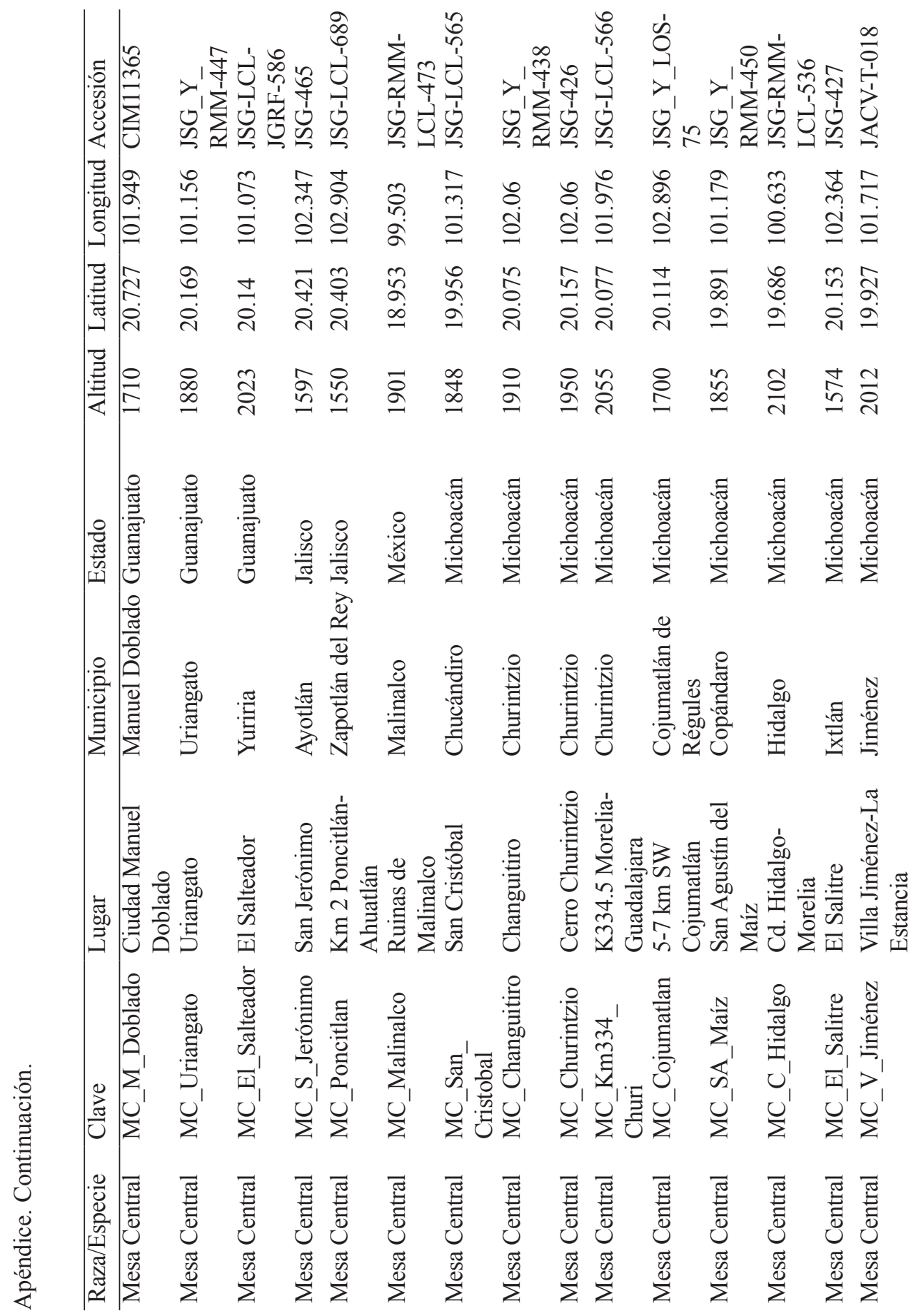


Acta Botanica Mexicana 111: 17-45 (2015)

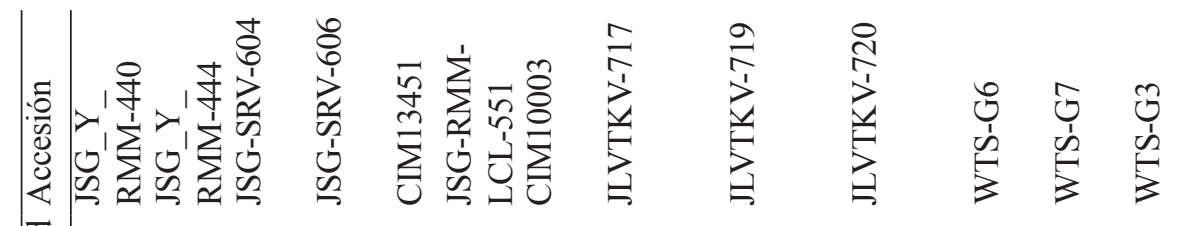

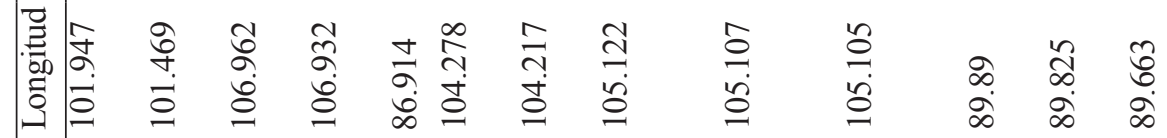

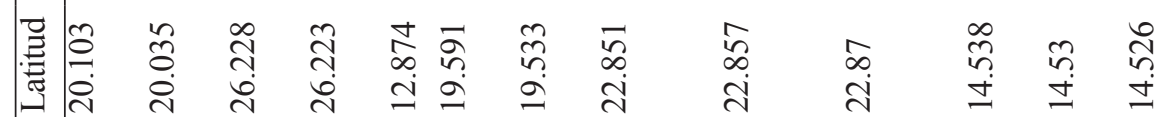

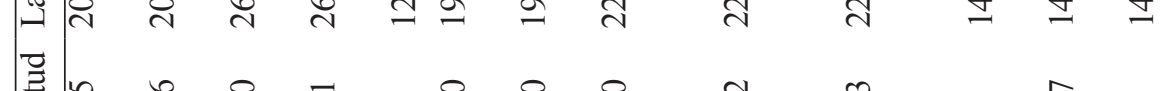

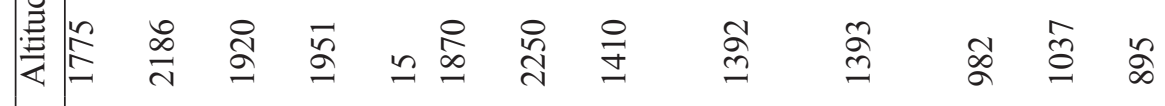

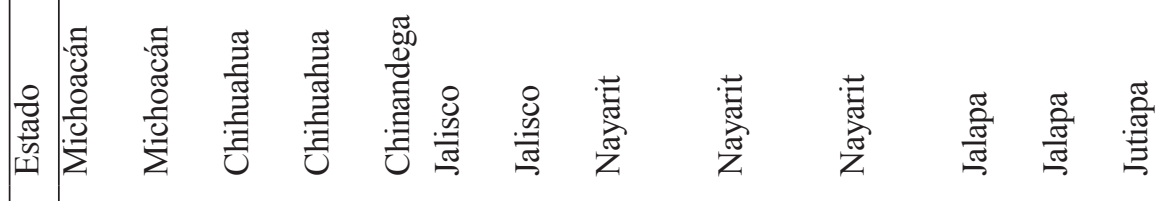

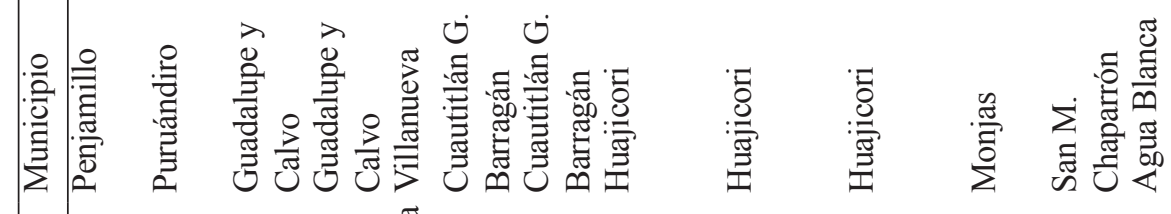

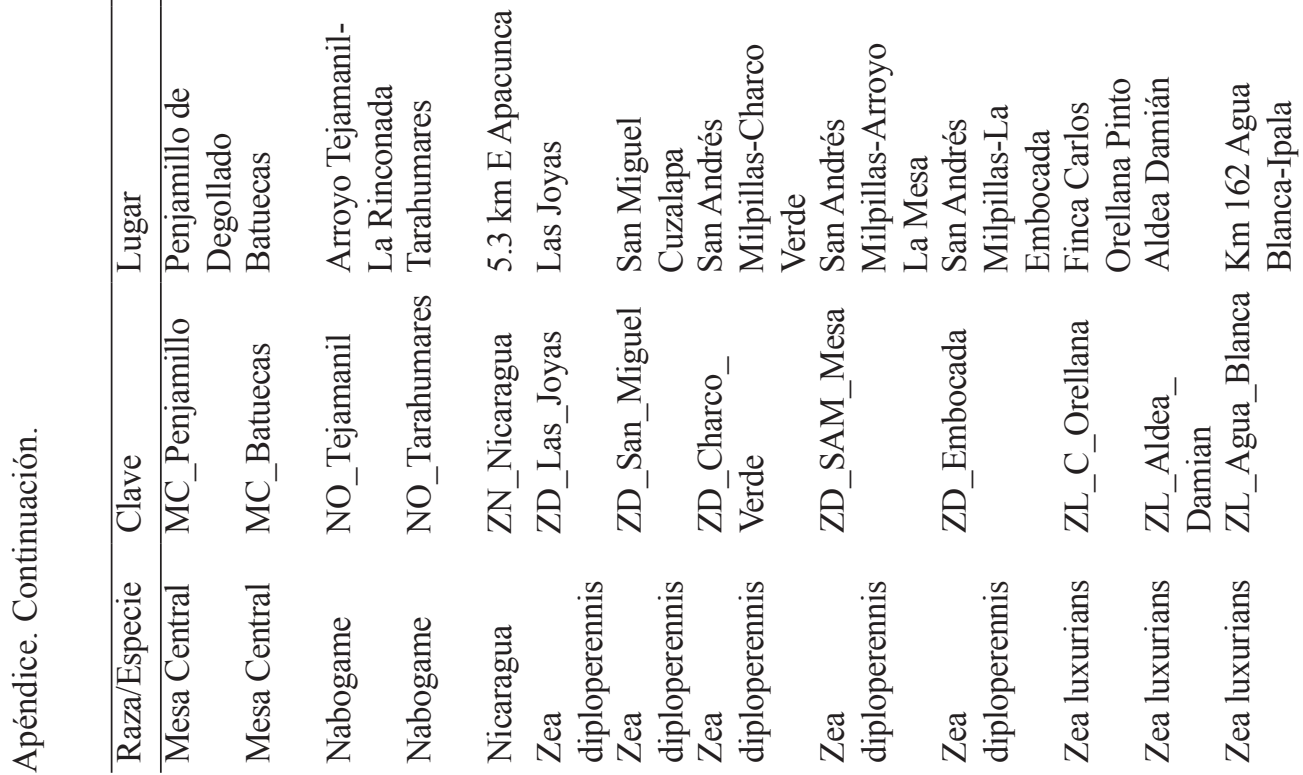


Torres Peña et al.: Relaciones entre poblaciones de teocintle (Zea spp.)

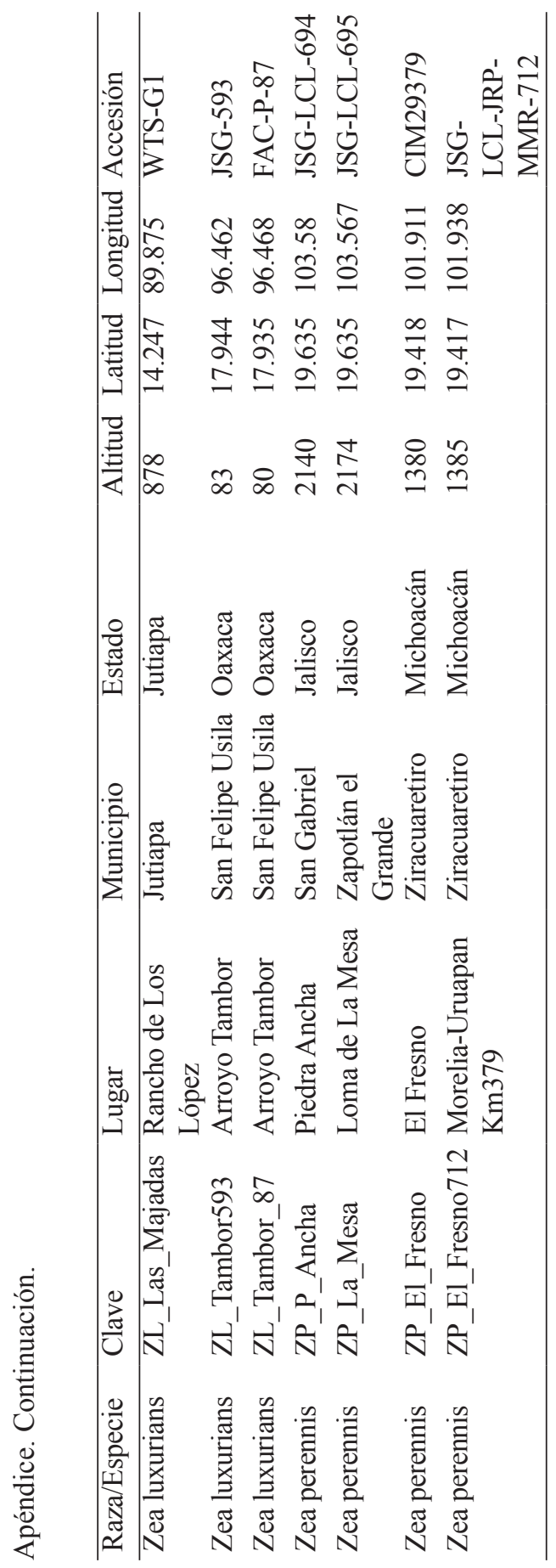

